\title{
Direct Energy Measurement Systems for Rotary Biomass Grinder - Hammermill
}

\author{
Manlu Yu, A. R. Womac, P.I. Miu, C. Igathinathane
}

University of Tennessee, Biosystems Engineering \& Soil Science, Knoxville, Tennessee, USA

\section{S. Sokhansanj}

Oak Ridge National Laboratory (ORNL), Tennessee, USA

\section{S. Narayan}

First American Scientific Co. (FASC), British Columbia, Canada

\author{
Written for presentation at the \\ 2006 ASABE Annual International Meeting \\ Sponsored by ASABE \\ Portland Convention Center \\ Portland, Oregon \\ 9 - 12 July 2006
}

\begin{abstract}
Understanding the energy requirement for biomass size reduction would be very significant for the process of converting the biomass to bioenergy. A hammermill was used for size reduction operations. One $12.7 \mathrm{~mm}$ size screen was applied to hammer mill for different particle size reduction. Torque Sensor was connected to the engine shaft to measure the transfer of torque and engine rotational speed RPM. Oak wood chips was the tested material. New surface generated by the cuts was evaluated. The research results will be used in practical applications, which are designing an ideal biomass size reduction apparatus for energy efficiency and better economics.
\end{abstract} Keywords. Biomass, Energy consumption, Size reduction, Particle size distribution, Hammer mill 


\section{Introduction}

The production of biomass energy sources is important in reducing worldwide fossil fuel demands because biomass is a renewable, and widely available resource. Many biomass materials such as switchgrass, corn stover, wheat straw, rice straw, alfalfa, hardwood, and sorghum stalks were used for biomass energy research studies. Switchgrass is viewed as a major future energy crop in the US. Corn stover and wheat straw is the most abundant field crop residues in the US (Little, 2002). Utilization of these crop residues as an energy source will supplement consumption of fossil fuels, and contribute less greenhouse gas emissions to the environment. Size reduction is an important pretreatment of biomass for energy conversion. Particle size reduction increases the total surface area, reduces pore size of the material and increases the number of contact point for inter-particle bonding in the compaction process (Little, 2002).

Understanding the energy requirement for biomass size reduction would be very useful in evolutionary the strategies to reduce input energy in process of converting the biomass to bioenergy. For size reduction, mechanical energy is needed to actually break the material and also to overcome friction between the moving parts of the machine. Different full-scale grinding machines have been applied in the lab and industry.

The interactions between factors such as biomass species, moisture content, particle size and shape, surface area before and after grinding, bulk density, feed rate, rotor speed, machine specification, clearance setting, and cutting speed are important for downstream processing. Energy consumption of grinding biomass depends on particle size distribution (initial/final particle size), moisture content, bulk and particle densities, feed rate of the material and machine variables (Lopo, 2002).

Moisture content had a positive correlation with specific energy consumption of wheat and barley straws, corn stover and switchgrass, the higher the moisture content; the higher was the specific energy consumption (Mani et al., 2004). Also, the moisture content had a positive correlation with specific energy consumption for alfalfa grinding (Balk, 1964).

Grinding energy consumption increased as the particle size decreased. Energy consumption decreased for grinding wheat straw, corn stover, and rice straw using grinder while the particle size distribution changing from finer to coarser (Arthur et al., 1982). The amount of energy used for milling to obtain small particles is relatively high. Higher power was consumed for fine grinding corn and grain sorghum by hammer mill (Martin and Behnke, 1984), The relationship for grinding energy with the length of wood cubes, the grinding energy increased greatly as the particle size is reduced (Holtzapple et al., 1989).

Screen opening size was the most significant factor affecting mill performance (Fang, Bolloni, Haque, and Spillman, 1997). And hammer mill screen opening have a significant effect on mean particle size (Pfost and Headley, 1971). Chopping energy increased as length of cut decreased forage harvester (Savoie, Trebly, Theriault, Wauthy, and Vigneault, 1989). 
Among the four materials - wheat and barley straw, corn stover and switchgrass at two moisture contents, switchgrass had the highest specific energy consumption, and corn stover had the least specific energy consumption at the same screen size hammer mill (Mani et al., 2004). They also found that grain sorghum residues required the least specific energy (Bargen, Lamb, and Kneels, 1981).

As grinding machine variables, for the hammer mill thickness effect, the specific energies increased as the hammermill thickness increased. The specific energies increased from 5.5 to 9.5 $\mathrm{Kw} . \mathrm{h} / \mathrm{t}$ for hammermill thickness increased from 1.59 to $8.00 \mathrm{~mm}$ (Vigneault, Rothwell, and Bougeois, 1992). Feeding rate has significant effect the energy consumption. Feet rate is 6-10 $\mathrm{kg} / \mathrm{s}$ for hammermill (O’Dogherty, 1982).

The speed has a significant effect on mean particle size (Pfost and Headley, 1971). The specific energies increased from 4.6 to $12.9 \mathrm{kw} . \mathrm{h} / \mathrm{t}$ for hammer tip speeds increased from 54 to $86 \mathrm{~m} / \mathrm{s}$ for a $6.35 \mathrm{~mm}$ thick hammer (Vigneault, Rothwell, and Bougeois, 1992).

Energy consumption based on weight was studied extensively (Liljedhal et al., 1961). Very little is known about energy consumption in the new generated surface area $\left(\mathrm{kJ} / \mathrm{m}^{2}\right)$ during the size reduction process.

\section{Objective}

The overall objective was to develop instrumented grinding system technology and techniques for direct energy measurement based on new generated surface area. The main benefit of this study is to better evaluate energy consumption for improved grinder designs.

\section{Materials and Methods}

\section{Materials}

Oak wood chips were used for the test.

\section{Methods}

The moisture content measurements were repeated for each specimen immediately after removal from the oven. According to the ASAE standards, a representative sample of at least $25 \mathrm{~g}$ was selected. The moisture content for each field sample was obtained by subjecting a sample to oven (air oven) drying at $103^{\circ} \mathrm{C}$ for $24 \mathrm{~h}$.

Oak wood chips samples before and after grinding (hammermill details in subsequent paragraphs) were sieved with 2-mm and 1-mm sieves. Three sub-samples were obtained: $>2 \mathrm{~mm}$ (sieve), $1-2$ $\mathrm{mm}$ (sieve), $<1 \mathrm{~mm}$ (sieve). These sub samples were individually analyzed, and data were pooled based on mass fractions to calculate representative particle sizes for samples before and after grinding. 
New generated surface area determination was calculated using two methods. First, the ASAE standard ANSI/ASAE S319.3 FEB03 and ANSI/ASAE S424.1 DEC01 was used. Calculation of particle size, surface area, and number of particles by mass calculations is based on the assumption that particle sizes of all ground feeds and feed ingredients are logarithmic-normally distributed. The size of particles can be reported in terms of geometric mean diameter (or median size) and geometric standard deviation by mass. The following equations can be used for geometric mean diameter or median size of particles by mass, $\mathrm{mm}$, or geometric mean diameter or median size of particles on $\mathrm{i}^{\text {th }}$ sieve, $\mathrm{mm}$,

$$
d_{g w}=\log ^{-1}\left[\frac{\sum_{i=1}^{n}\left(W_{i} \log \overline{d_{i}}\right)}{\sum_{i=1}^{n} W_{i}}\right] ;
$$

where:

$d_{i} \quad$ is norminal sieve aperture size of the $\mathrm{i}^{\text {th }}$ sieve, $\mathrm{mm}$

$d_{i+1} \quad$ is norminal sieve aperture size in next larger than $\mathrm{i}^{\text {th }}$ sieve, $\mathrm{mm}$

$d_{g w} \quad$ is geometric mean diameter or median size of particles by mass, $\mathrm{mm}$, is geometric mean diameter or median size of particles on $\mathrm{i}^{\text {th }}$ sieve, $\mathrm{mm}$, or is $\left(d_{i} \times d_{i+1}\right)^{1 / 2}$

$W_{i} \quad$ is mass in $\mathrm{i}^{\text {th }}$ sieve, $\mathrm{g}$

$\mathrm{N}$ is number of sieves +1 (pan)

The equation for estimating the total surface area of particles in a charge is calculated as:

$$
A_{s t}=\frac{\beta_{s} W_{t}}{\beta_{v} \rho} \exp \left(4.5 \delta_{\ln }^{2}-\ln \mu_{g w}\right)
$$

where:

$A_{s t} \quad$ is estimated total surface area of a charge, $\mathrm{cm}^{2}$

$\beta_{s} \quad$ is shape factor for calculating surface area of particles. Cubical, $\beta_{s}=6$; Spherical, $\beta_{s}=\pi$

$\beta_{v} \quad$ is shape factor for calculating volume of particles. Cubical, $\beta_{v}=1$; Spherical, $\beta_{v}=\pi / 6$

$\rho \quad$ is particle density of the material, $\mathrm{g} / \mathrm{cm}^{3}$

$\sigma_{l n} \quad$ is log-normal geometric standard deviation of parent population by mass in natural logarithm, use $\mathrm{S}_{\mathrm{ln}}$ as an estimate

$\mu_{g w} \quad$ is geometric mean particle diameter of parent population by mass, cm, use $d_{g w}$ as an estimate

$W_{t} \quad$ is a mass of a change, $\mathrm{g}$

Simply the number of particle in charge is calculated as:

$$
N_{t}=\frac{W_{t}}{\beta_{v} \rho} \exp \left(4.5 \sigma_{\ln }^{2}-3 \ln \mu_{g w}\right)
$$

where: 
$N_{t} \quad$ is the number of particles in a charge

For the second method the effect of particle shape and size was examined in determining particle surface area:

For particle assumption 1, the $>2 \mathrm{~mm}$ subsample particles were assumed flat rectangle with assumed major dimensions of the square root of upper sieve size times lower sieve opening width, with upper sieve assumed as $3 \mathrm{~mm}$. Particle thickness was measured as $0.289 \mathrm{~mm}$ for $>$ $2 \mathrm{~mm}$ particles. $1-2 \mathrm{~mm}$ and $<1 \mathrm{~mm}$ subsamples were assumed as spherical of diamater size determined as the square root of upper sieve size times lower sieve opening width.

For particle assumption 2, subsample $>2 \mathrm{~mm}$ particles were assumed flat rectangle with assumed major dimensions of the square root of upper sieve size times lower sieve opening width, with upper sieve assumed as $3 \mathrm{~mm}$. Particle thickness was measured as $0.289 \mathrm{~mm}$ for $>2 \mathrm{~mm}$ particles. Subsample 1-2 $\mathrm{mm}$ were assumed as flat rectangle of measured particle thickness, length and width of assumed sieve representative size which equals to the square root of product of upper and low seive sizes, Particle on seive $<1 \mathrm{~mm}$ were assumed as flat rectangle of measured particle thickness, length and width of assumed sieve representative size which equals to the square root of product of upper and low seive sizes.

For particle assumption 3, subsample $>2 \mathrm{~mm}$ particles were assumed flat rectangle with assumed major dimensions of the square root of upper sieve size times lower sieve opening width, with upper sieve assumed as $3 \mathrm{~mm}$. Particle thickness was measured as $0.289 \mathrm{~mm}$ for $>2 \mathrm{~mm}$ particles. Subsample 1-2 $\mathrm{mm}$ were assumed as flat rectangle of one-half $(1 / 2)$ measured particle thickness, length and width of assumed sieve representative size which equals to the square root of product of upper and low seive sizes, Particle on seive $<1 \mathrm{~mm}$ were assumed as flat rectangle of one-half $(1 / 2)$ measured particle thickness, length and width of assumed sieve representative size which equals to the square root of product of upper and low seive sizes.

Sample area calculation follows:

$$
\begin{aligned}
& A_{\text {sin gle }}=4 \pi R^{2} \\
& V_{\text {sin gle }}=4 / 3 \pi R^{3} \\
& W_{\text {sampleweight }}=W_{\text {sin galweight }} * N=V_{\text {sin gle }} * \rho^{*} N \\
& N=\frac{W_{\text {sampleweight }}}{V_{\text {sin gal }} * \rho} \\
& A_{\text {total In ew }}=N^{*} A_{\text {sin gal }}
\end{aligned}
$$

where:

$A_{\text {singal }}$ is single particle surface area

$V_{\text {singal }}$ is single particle volume

$R \quad$ is the single particle radius $\mathrm{D} / 2$

$W_{\text {sampleweight }}$ is the sample weight on certain sieve

$\rho \quad$ is the density 
Energy consumption determination is based on new generated surface area $\left(\mathrm{kJ} / \mathrm{m}^{2}\right)$, which is energy/area. We integrate torque/speed over time to obtain the power.

Power is represented as:

$$
\begin{aligned}
& K W(\text { power })=\frac{\tau(\text { inlb }) \times V(\mathrm{rpm})}{63025} \\
& \frac{\text { Power }}{\text { Feedrate }}=\mathrm{kw} / \mathrm{kg} / \mathrm{s}
\end{aligned}
$$

Therefore, the energy consumption determination based on new generated surface area $\left(\mathrm{kJ} / \mathrm{m}^{2}\right)$ is obtained.

An instrumented grinder system was developed for this research study. Instrumented size reduction of biomass used direct measures of torque and rpm of rotary grinder - hammermill in grinding process. One $12.7 \mathrm{~mm}$ size screen in a hammer mill was applied for particle size reduction. Torque sensor was connected to the engine shaft to measure the transfer of torque and engine rotational speed RPM. A data acquisition system collected the data through Labview software for analysis and record. The input material feed rate was also measured. The values obtained from these measurements will be used in calculation. The output biomass particle size distributions were measured. Particle area was calculated as described above.

A Schutte heavy-duty hammer mill shreds and crushes the materials being ground by means of high-speed-rotating hammer tips. Six free-swinging hammers mounted on a shaft rotating about an axis perpendicular to the direction of feeding material through inlet opening. The mills are normally operated at a maximum 3600 RPM.

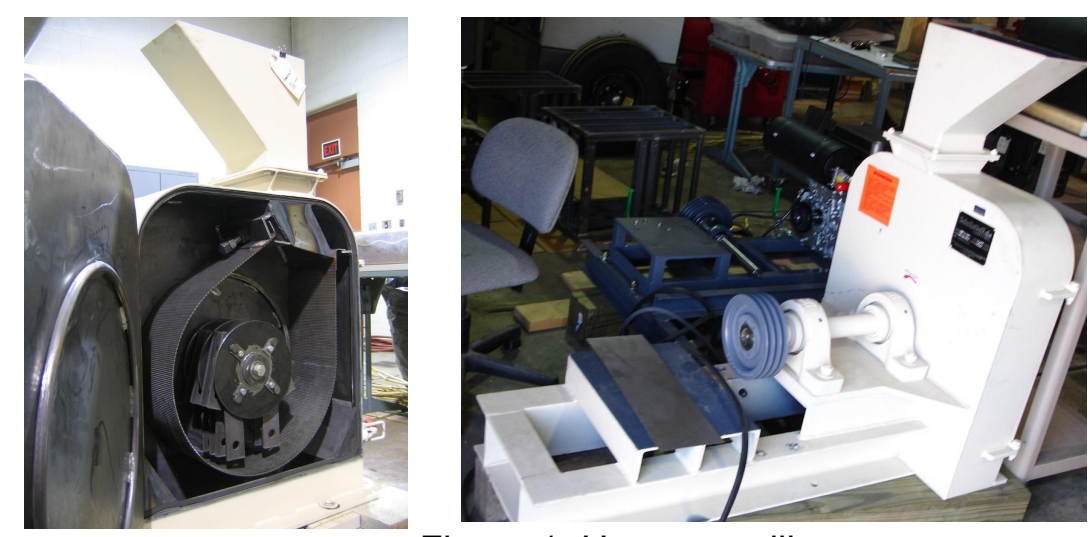

Figure 1. Hammer mill

A PCB Rotating Transformer Shaft Torque Sensor (Model 4205-01A PCB PIEZOTRONICS ) was directly coupled to the engine shaft required measured the transfer of power, torque, and 
speed between them. The rationale for in-line torque selection is to directly measure the power. Once properly installed between engine and machine, the torque sensor needs to be connected through the proper cable to the signal conditioner (Model 8120-400 A PCB PIEZOTRONICS AC Excitation Strain Gage Signal Conditioner). When this is done and signal conditioner is connected to the power source and turned on and stabilized, operational calibration can proceed. Torque sensor has a different strain gauge bridge resistance and a different full-scale output.

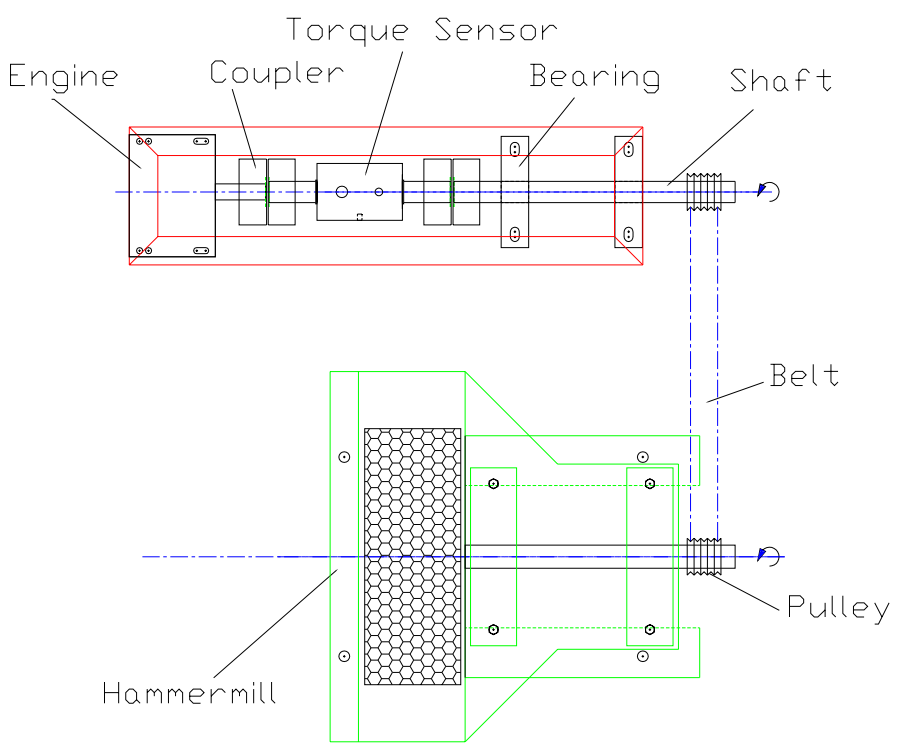

Figure 2. Layout/engine/incorporate of sensors

The speed sensor is used with rotary torque sensor to provide a measurement of rotational speed (engine shaft revolutions RPM). When used with PCB torque sensors, this unit will provide a sine wave output signal.

LabVIEW will be used to communicate with hardware as data acquisition. In LabVIEW, we build a user interface, or front panel, with controls and indicators. After building the user interface, we add code using VIs and in structures to control the front panel objects. The block diagram contains this code. Torque versus time curve and RPM versus time curve are obtained while processing the tests.

\section{Results and discussion}

Using the ASAE standard method to calculate the new generated area, the area is $10.87\left(\mathrm{~m}^{2} / \mathrm{kg}\right)$ of before grinding and $11.93\left(\mathrm{~m}^{2} / \mathrm{kg}\right)$ of after grinding, the new generated surface area per weight increases $9.8 \%$. 
Using second area calculation method, the following results were reached:

Table 1. Results of area determinations on input oak wood chips

\begin{tabular}{|c|c|c|c|c|c|}
\hline \multicolumn{6}{|c|}{ Grinding input material } \\
\hline \multicolumn{2}{|c|}{ Particle Assumption 1} & \multicolumn{2}{|c|}{ Particle Assumption 2} & \multicolumn{2}{|c|}{$\begin{array}{l}\text { Particle Assumption } 3 \\
\end{array}$} \\
\hline $\begin{array}{c}\text { Input } \\
\text { material } \\
\text { particle size }\end{array}$ & $\begin{array}{l}\text { A/weight } \\
\left(m^{\wedge} 2 / \mathrm{kg}\right)\end{array}$ & $\begin{array}{l}\text { Input material } \\
\text { particle size }\end{array}$ & $\begin{array}{l}\text { A/weight } \\
\left(m^{\wedge} 2 / \mathbf{k g}\right)\end{array}$ & $\begin{array}{l}\text { Input material particle } \\
\text { size }\end{array}$ & $\begin{array}{l}\text { A/weight } \\
\left(m^{\wedge} 2 / \mathbf{k g}\right)\end{array}$ \\
\hline $\begin{array}{c}\text { Particle on } \\
\text { sieve }>2 \\
\mathrm{~mm} \text { - assume } \\
\text { as flat } \\
\text { rectangle }\end{array}$ & 10.549 & $\begin{array}{c}\text { Particle on seive }>2 \\
\text { mm - assume as flat } \\
\text { rectangle }\end{array}$ & 11.471 & $\begin{array}{l}\text { Particle on seive }>2 \mathrm{~mm} \text { - } \\
\text { assume as flat rectangle }\end{array}$ & 11.471 \\
\hline $\begin{array}{l}\text { Particle on } \\
\text { seive } 1-2 \\
\mathrm{~mm} \text { - assume } \\
\text { as sphere of } \\
\text { size = Sqroot } \\
\text { of product of } \\
\text { upper and } \\
\text { low sieve } \\
\text { sizes }\end{array}$ & 6. 020 & $\begin{array}{l}\text { Particle on seive } 1-22 \\
\text { mm - assume as flat } \\
\text { rectangle of measured } \\
\text { particle thickness, } \\
\text { length and width of } \\
\text { assumed sieve } \\
\text { representative size = } \\
\text { Sqroot of product of } \\
\text { upper and low seive } \\
\text { sizes }\end{array}$ & 14.562 & $\begin{array}{l}\text { Particle on seive } 1-2 \mathrm{~mm}- \\
\text { assume as flat rectangle of } \\
0.5 \text { original measured } \\
\text { particle thickness, length } \\
\text { and width of assumed } \\
\text { sieve representative size = } \\
\text { Sqroot of product of upper } \\
\text { and low seive sizes }\end{array}$ & 25. 111 \\
\hline $\begin{array}{l}\text { Particle on } \\
\text { seive }<1 \\
\mathrm{~mm}-\text { assume } \\
\text { as sphere of } \\
\text { size = Sqroot } \\
\text { of product of } \\
\text { upper and } \\
\text { low sieve } \\
\text { sizes }\end{array}$ & 12.039 & $\begin{array}{l}\text { Particle on seive }< \\
1 \mathrm{~mm} \text { - assume as flat } \\
\text { rectangle of measured } \\
\text { particle thickness, } \\
\text { length and width of } \\
\text { assumed sieve } \\
\text { representative size = } \\
\text { Sqroot of product of } \\
\text { upper and low seive } \\
\text { sizes }\end{array}$ & 18.575 & $\begin{array}{l}\text { Particle on seive }<1 \mathrm{~mm}- \\
\text { assume as flat rectangle of } \\
0.5 \text { original measured } \\
\text { particle thickness, length } \\
\text { and width of assumed } \\
\text { sieve representative size = } \\
\text { Sqroot of product of upper } \\
\text { and low seive sizes }\end{array}$ & 29.124 \\
\hline $\begin{array}{l}\text { Cumulative } \\
\text { area by mass } \\
\text { fraction on } \\
\text { each sieve }\end{array}$ & 9. 799 & & 13. 382 & & 17.544 \\
\hline
\end{tabular}


Table 2. Results of area determinations on output oak wood chips

\begin{tabular}{|c|c|c|c|c|c|}
\hline \multicolumn{6}{|c|}{ Grinding output material } \\
\hline \multicolumn{2}{|c|}{ Particle Assumption 1} & \multicolumn{2}{|c|}{ Particle Assumption 2} & \multicolumn{2}{|c|}{ Particle Assumption 3} \\
\hline $\begin{array}{l}\text { Output } \\
\text { particle size } \\
\text { (HM) }\end{array}$ & $\begin{array}{l}\text { A/weight } \\
\left(m^{\wedge} 2 / \mathrm{kg}\right)\end{array}$ & $\begin{array}{l}\text { Input material } \\
\text { particle size }\end{array}$ & $\begin{array}{l}\text { A/weight } \\
\left(m^{\wedge} 2 / \mathrm{kg}\right)\end{array}$ & $\begin{array}{l}\text { Input material particle } \\
\text { size }\end{array}$ & $\begin{array}{l}\text { A/weight } \\
\left(m^{\wedge} 2 / \mathrm{kg}\right)\end{array}$ \\
\hline $\begin{array}{c}\text { Particle on } \\
\text { sieve }>2 \\
\text { mm - assume } \\
\text { as flat } \\
\text { rectangle }\end{array}$ & 0 & $\begin{array}{c}\text { Particle on seive }>2 \\
\mathrm{~mm} \text { - assume as flat } \\
\text { rectangle }\end{array}$ & 0 & $\begin{array}{l}\text { Particle on seive }>2 \mathrm{~mm}- \\
\text { assume as flat rectangle }\end{array}$ & 0 \\
\hline $\begin{array}{l}\text { Particle on } \\
\text { seive 1-2 } \\
\mathrm{mm} \text { - assume } \\
\text { as sphere of } \\
\text { size = Sqroot } \\
\text { of product of } \\
\text { upper and } \\
\text { low sieve } \\
\text { sizes }\end{array}$ & 6.301 & $\begin{array}{l}\text { Particle on seive } 1-2 \\
\text { mm - assume as flat } \\
\text { rectangle of measured } \\
\text { particle thickness, } \\
\text { length and width of } \\
\text { assumed sieve } \\
\text { representative size = } \\
\text { Sqroot of product of } \\
\text { upper and low seive } \\
\text { sizes }\end{array}$ & 14.562 & $\begin{array}{l}\text { Particle on seive } 1-2 \mathrm{~mm} \\
\text { - assume as flat rectangle } \\
\text { of } 0.5 \text { original measured } \\
\text { particle thickness, length } \\
\text { and width of assumed } \\
\text { sieve representative size }= \\
\text { Sqroot of product of upper } \\
\text { and low seive sizes }\end{array}$ & 25.111 \\
\hline $\begin{array}{l}\text { Particle on } \\
\text { seive }<1 \\
\text { mm - assume } \\
\text { as sphere of } \\
\text { size }=\text { Sqroot } \\
\text { of product of } \\
\text { upper and } \\
\text { low sieve } \\
\text { sizes } \\
\end{array}$ & 3.151 & $\begin{array}{c}\text { Particle on seive < } \\
1 \mathrm{~mm} \text { - assume as flat } \\
\text { rectangle of measured } \\
\text { particle thickness, } \\
\text { length and width of } \\
\text { assumed sieve } \\
\text { representative size = } \\
\text { Sqroot of product of } \\
\text { upper and low seive } \\
\text { sizes } \\
\end{array}$ & 18.575 & $\begin{array}{l}\text { particle on seive }<1 \mathrm{~mm}- \\
\text { assume as flat rectangle of } \\
0.5 \text { original measured } \\
\text { particle thickness, length } \\
\text { and width of assumed } \\
\text { sieve representative size }= \\
\text { Sqroot of product of upper } \\
\text { and low seive sizes }\end{array}$ & 29.124 \\
\hline Total & 4.926 & & 16.313 & & 26.862 \\
\hline
\end{tabular}

For assumption 1, there was a lack of reasonableness of difference in added surface area due to grinding - which was (negative) $-49.7 \%$. Area after grinding should be greater than the area before grinding. This method of calculation does not yield rationale results. The flaw is assuming a diameter that was greater than the thickness of material being cut.

For assumption 2, this result is more reasonable than method 1 . The magnitude of area was greater because the reduced thickness resulted in many more particles for the same volume of solid wood. The new generated surface area per weight increases $21.9 \%$ with the area of 16.3 $\left(\mathrm{m}^{2} / \mathrm{kg}\right)$ before grinding and $13.3\left(\mathrm{~m}^{2} / \mathrm{kg}\right)$ after grinding.

For assumption 3, this result is reasonable. The magnitude of area was even greater than the method 2 because the reduced thickness twice resulted in even more particles for the same volume of solid wood. The new generated surface area per weight increases $53.1 \%$ with the area of $26.86\left(\mathrm{~m}^{2} / \mathrm{kg}\right)$ before grinding and $17.54\left(\mathrm{~m}^{2} / \mathrm{kg}\right)$ after grinding. This highlights the importance of particle thickness, and the need to closely examine and measure particle dimensions. 


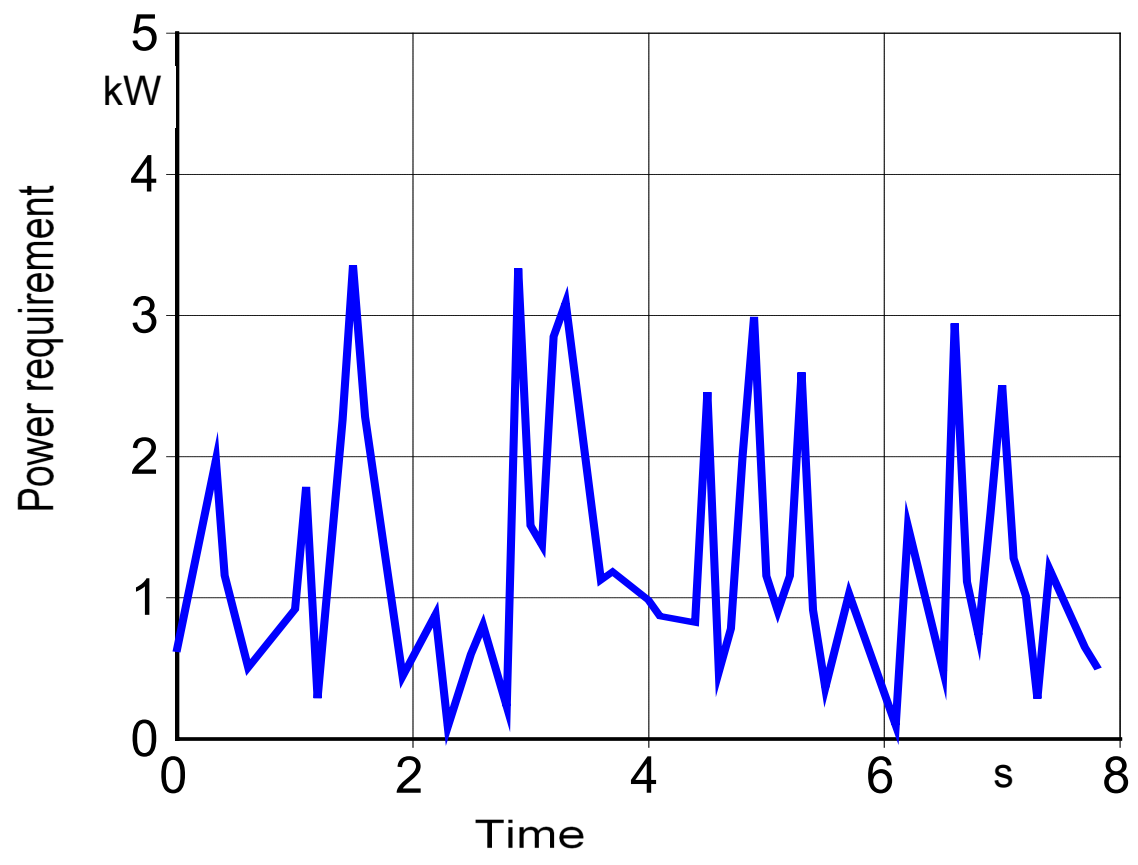

Figure 4. Power requirement for cutting wood chips using hammer mill

The energy consumption can be calculated by integrating the power and time in Figure 4.

Direct measurement of grinder input power is being emphasized to evaluate grinder. The developed experimental instrument grinding system is very beneficial to evaluate the energy consumption. The machine specifications effect the energy consumption for grinding. Grinding more materials using this system will be future studied in order to category the energy consumption.

\section{Conclusions:}

1. Existing methods for quantifying particle area are inadequate.

2. Accurate particle surface area requires accurate representation of particle shape, and the need to closely examine the particles closely.

3. Grinder power can be directly measured with a torque sensor and speed measurement.

\section{References}

Balk, W.A. 1964. Energy requirements for dehydrating and pelleting coastal Bermuda grass.

Transactions of the ASAE. 4: 349-351 and 355. 
Fang, Q., I. Bolloni, E. Haque, and C. K. Spillman. 1997. Comparison of energy efficiency between a roller mill and a hammer mill. Appl. Eng. In Agric. 13(35): 631-635.

Holtzapple, M.T. et al. 1989. Energy requirements for the size reduction of poplar and aspen wood. Biotechnology and Bioengineering (33):207-10.

Arthur, J.F. et al.1982. Tub grinder performances with crop and forest residues. Transactions of the ASAE. 25(6): 1488-1494.

Little, A.D. 2002. Aggressive grouth in the use of bioderived energy and products in the United States by 2010. Final Report. www.adltechnology.com; accessed on March, 2002.

Lopo, P. 2002. The right grinding solution for you: roll, horizontal or vertical. Feed Management;53(3):23-6.

Martin S. and Behnke K. 1984. Grinding efficiency and particle size effects on feed manufacturing operations. ASAE Paper No. 84-3524, ASAE, St. Joseph, MI 49085.

O'Dogherty, M.J. 1982. A review of research on forage chopping. Journal of Agricultural Engineering Research 27(4): 267-289.

Pfost, H.B., and V.E. Headley. 1971. Use of logarithmic normal distribution to describe hammermill performance. Trans. ASAE 14(3): 531-535.

Savoie, P., D. Trebly, R. Theriault, J.M. Wauthy, C. Vigneault. 1989. Forage chopping energy vs length of cut. Trans. ASAE 32(2): 437-442.

Mani, S. et al. 2004. Grinding performance and physical properties of wheat and barley straws, corn stover and switchgrass. Biomass and Bioenergy 27: 339-352.

Vigneault, C., T.M. Rothwell, G. Bougeois. 1992. Hammer mill grinding rate and energy requirement for thin and conventional hammers. Canadian Agricultural Engineering. 34(2): 203-6.

Von Bargen K, M. Lamb, D.E., Kneels. 1981.Energy requirements for particle size reduction of crop residue. Paper no. 81-4062.St. Joseph, MI: American Society of Agricultural Engineers; 